Open Access

\title{
Consequences of social mobility on social relationships: a case study of successful rural migrants in Beijing
}

Na Liu

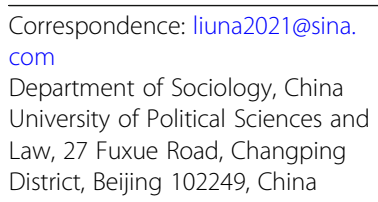

Correspondence: liuna2021@sina. com

Department of Sociology, China University of Political Sciences and Law, 27 Fuxue Road, Changping District, Beijing 102249, China

\begin{abstract}
The impact of social mobility on social relationships is a neglected area of mobility studies in China. Drawing on intensive interviews with 30 migrant families in Beijing, this research aims to investigate the effect of social mobility on the social life and interpersonal relationships of successful migrants, especially regarding family, friends, and locals. It has been shown that the economic success of the interviewees did not estrange them from kin but rather strengthened their ties and obligations toward each other. Their mode of association still followed the principle of chaxu geju. Their friendship circles, however, changed significantly. Old ties that could not move upwards at the same pace were usually left behind. Despite these significant changes, however, their social relationships beyond kin were mainly limited to rural migrants. Very few socialized with or established contacts with the local people in Beijing. The economic success of the migrants did not bring social integration. Their social adaptation was largely a process of assimilating with social groups formed by people similar to themselves rather than a process of integrating into the already established urban classes.
\end{abstract}

Keywords: Social mobility, Social relationships, Rural migrants

\section{Introduction}

The Chinese society has experienced dramatic changes after the 1978 economic reforms that aimed to transform the country's centrally planned economy into a market economy. In the process, state control over the population's mobility eased and the migration of rural people to cities increased steadily. By the end of 2017, the migrant population amounted to over 0.244 billion (according to the 2018 Report on China's Migrant Population Development released by the National Health Commission of the People's Republic of China). This large number of rural migrants attracted considerable attention in academic circles. Numerous studies concerning rural migrants have emerged (Solinger 1999; Zhang 2001; Li 2003; Yue et al. 2013; Wang et al. 2016; etc.). Nevertheless, existing work in this area focuses primarily on institutional barriers to rural migrants and their vulnerability and marginalization in cities. Few of them have observed the issues from the perspective of social mobility. Empirical studies have frequently shown that rural migrants do not just react passively to broad social structures. Rather, they are very active in

(c) The Author(s). 2019 Open Access This article is distributed under the terms of the Creative Commons Attribution 4.0 International License (http://creativecommons.org/licenses/by/4.0/), which permits unrestricted use, distribution, and reproduction in any medium, provided you give appropriate credit to the original author(s) and the source, provide a link to the Creative Commons license, and indicate if changes were made. 
seeking opportunities to change their lives. Thus, while some migrants live difficult lives in cities, others have already put down roots in cities and have even acquired urban citizenship, having become "real" urbanites (Xiang 2005; Li 2011).

Moreover, China's social structure has changed dramatically after its economic reforms. With the rapid upward shift of occupational structures, better opportunities are emerging. Such change is mainly boosted by the quickly growing private economy and the rapid development of new social classes, namely the self-employed, private entrepreneurs, and managers. These classes are becoming an important part of China's newly formed middle class. Many former peasants have successfully squeezed into these classes by engaging in business (Lu 2004; Li 2011). So far, little attention has been paid to this group of people. This research, based on in-depth interviews with 30 successful migrant families in Beijing, attempts to explore the social life of these successful migrants, especially with regard to the consequences of social mobility on their social relationships. How did they socialize with kin and friends after they got rich? Did their economic success facilitate their integration into the local community? The interviews thus sought to uncover data regarding (1) the composition of the interviewees' socializing circles and (2) the impact of economic success on the social integration of the migrants in their new urban communities.

This paper consists of five sections. It begins with a review of key sources, followed by a methodology section and three main empirical sections. The first empirical section covers the sociability of the interviewees with kin. Their interaction with their parents, siblings, and extended kin are examined. The second and third empirical sections explore the interviewees' associations with their friends and locals, especially regarding the effect of mobility on their friendship circles and social integration.

\section{Theoretical link-the consequences of social mobility on social relationships}

Social mobility, indicated by the change of one's social, economic, or political position, is expected to affect, to a certain degree, the relationship structures of a mobile individual (Blau 1956; Goldthorpe et al. 1987). The main debates in the literature tend to concentrate on the extent to which social mobility affects one's interpersonal relationships or social life. The dissociative hypothesis maintains that social mobility tends to bring a mobile individual into a stage of social isolation or marginality (Sorokin 1998; Lipset and Bendix 1967; Blau 1956). Proponents of this view argue that there are two reasons for this: on the one hand, social mobility is more likely to result in the disruption of old relationships, since upwardly mobile persons are more likely to neglect or break their old ties, while downwardly mobile persons are more likely to be neglected by their old ties; on the other hand, the mobile may not be easily accepted by those already established in the new social milieu. In Blau's (1956, p. 290) words, the mobile "are marginal men, in some respects out of tune with others both in their new and original strata in the occupational hierarchy." This marginal position thus in turn makes it very difficult for them to establish interpersonal relationships, hence inhibiting their social integration.

This hypothesis is challenged by other mobility researchers (Goldthorpe et al. 1987; Higginbotham and Weber 1992), among whom, Goldthorpe et al. perhaps are the most influential. Goldthorpe's study on social mobility in Britain showed that although social mobility gives rise to some changes in interpersonal relationships, it exerts no disruptive effects 
at all. To elaborate, they divided social relationships into two types, namely kinship ties and associate or friendship ties.

In the sphere of kinship relations, they $(1987$, p. 160) found that no evidence indicated that "mobile individuals are distinctive in their degree of isolation from kin." The mobile have no intention to leave kin behind. On the contrary, upwardly mobile individuals who have kin in their proximity are more likely to resort to kin than those who are stable in their class positions. Kinship relationships thus are in fact an important source of support for the mobile. Nevertheless, this is not to say that social mobility has no influence on kinship relationships at all. Their data showed that as upward mobility is usually accompanied by geographic mobility, the mobile tend to have less interaction with kin due to physical separation. In addition, as a consequence of choice as well as constraint, they have "the least contact with kin in their leisure activities," whether their kin live nearby or far away (Goldthorpe et al. 1987, p. 165). The separation of their kinship circle and friendship circle therefore results in a more segmented social network for the mobile. Their networks thus may be more demanding given that they usually need to adjust between two different worlds.

Outside the family, Goldthorpe et al. (1987) found that upwardly mobile individuals are more likely to become detached from non-mobile members of their class of origin, reflected in the fact that the majority of their recreational associations and good friends are members of their class of destination. This is especially the case for those who have moved up via direct routes. Yet, the researchers' material also revealed that a significant number of associates and friends of mobile individuals are old ties made before they became mobile, a phenomenon that seems to go against their previous statement, namely, that the upwardly mobile are more likely to drop old associates and friends. Goldthorpe et al. (1987, p. 199) assumed that two interpretations may be possible in explaining this seemingly contradictory phenomenon. One is that mobile individuals may have a bias toward maintaining relationships with persons in higher-level positions. The second is that, more possibly, they may have sustained ties with persons who have moved up in the same course as they themselves have. In other words, they do drop those who remain stable, but not those who move up alongside them. ${ }^{1}$ Goldthorpe et al. (1987, p. 200) laid particular stress on the second interpretation, arguing that this assumption can be strongly supported by the high rates of upward mobility in modern society. That is to say, in an expanding industrial society, upwardly mobile persons are so numerous that they are most likely surrounded by many others who have followed a similar social trajectory.

This fact, Goldthorpe et al. argued, also indicates that the mobile are less likely to experience social isolation or marginality, because even though they are rejected by those already established or become more or less estranged from their non-mobile friends, they still enjoy great opportunities to socialize with each other. Therefore, they may encounter little problems with assimilation. Thus, together with what has been found on

\footnotetext{
${ }^{1}$ Goldthorpe et al. (1987, p. 199) explained: What, therefore, one is led to conclude is either that our upwardly mobile respondents, as part perhaps of some process of anticipatory socialization, had quite frequently formed relationships with 'established' service-class persons in the period before they had themselves gained access to this class; or, as we would think generally more important, that many of their current service-class associates and friends who are of long standing had also, like themselves, made their way into the service class from lower class origins and could thus be met en route on a basis of approximate social equality, whether in the course of their education or of their earlier working lives.
} 
kinship relations, Goldthorpe et al. (1987, p. 204) concluded that in modern society social mobility tends to "extend and diversify, rather than to undermine, the individual's pattern of social involvement," bet it at the primary level or the secondary level.

Thus, how do these findings stand up in societies like China? Do the key arguments outlined above apply to the Chinese case as well? The empirical study in this research appears to suggest that although Goldthorpe's arguments are largely supported in this case study, many aspects of their theories still need to be remedied. For example, despite distinguishing kinship ties from friendship ties, Goldthorpe et al. did not look into them in detail. The effects of social mobility on kinship ties may be quite different among parent-child ties, siblings and extended kin, as well as between close friends and ordinary friends. This is especially the case for Chinese society. It has been argued that in Chinese society individuals exist only in relation to others, and their relationships with different people are constrained by different sets of normative expectations and responsibilities (Zhou 2018; Xiao 2014). Fei (1985) defined this pattern of social interactions as "chaxu geju" (differentiated modes of association), maintaining that Chinese society is organized by concentric relationship circles that are formed on the basis of xueyuan (blood bonds) and diyuan (native-place bonds). These concentric relationship circles are like spreading ripples in a pool agitated by a stone, extending from family to relatives, friends, acquaintances, and so on. The family circle, which constitutes the core of these concentric circles, is the most important and demanding. Obligations and rights are "graded and fall off in intensity" when moving from the inner circle (Fei 1985; Fukuyama 1995, p. 93). Individuals evaluate and maneuver their relationships to others according to their different positions in these concentric circles. Social mobility, therefore, may have considerably different impacts on different types of social ties.

Fei's arguments are well received in the literature. Yet, with the transformation of Chinese society, some scholars argue that the nature of chaxu geju has changed, and economic benefits have replaced familism, becoming the primary factor in determining the order of chaxu geju. They name the new tendency as "the rationalization of chaxu geju" (Yang and Hou 1999) or "the new chaxu geju" (Xiao 2014). Some scholars, however, disagree, arguing that the importance of economic benefits can by no means be overstated. Interests may play an important role in shaping social relations in contemporary China, but intense family ties still remain the core of chaxu geju in both rural and urban China (Zhang 2008; Ma et al. 2011; Tang and Chen 2012). Then what really matters? For those who have experienced long-range upward mobility, kinship relations may not be able to provide them with crucial help. Thus, do they tend to focus on economic benefits and become estranged from their kin? Or do they tend to maintain close relationships with their kin and try their best to help them? How do they deal with old friends who are left behind? Does their economic success facilitate their integration into local society? This paper aims to clarify these issues by detailing the interactions of the interviewees with their kin, friends, and locals. The following sections will move on to the empirical study of this research, beginning with a description of the methodology that underpins this study.

\section{Fieldwork and sample}

This research is based on in-depth interviews with 30 successful migrant business families in Beijing. As rural migrants are excluded from the formal sector of the economy, 
self-employment and small businesses have become their alternative options as well as their main way to achieve success. Given this consideration, our sample targeted migrant business families, defined as families whose assets were worth more than five million yuan and whose per capita disposable incomes were higher than 200,000 yuan. ${ }^{2}$ Finding an eligible sample was not an easy task, however, despite a large number of migrant businesspeople in Beijing. On the one hand, it is very difficult to know one's economic status in a large metropolis like Beijing, especially when it comes to mobile individuals. On the other hand, people can be very unwilling to talk about their life stories with a researcher who is a stranger to them. As a result, our sample was developed through a networking strategy, departing from the point of the author's own social circle. The author's contacts led her to meet a number of initial participants who, in turn, found other potential subjects. In this way, one contact led to another, thereby enlarging the potential sample pool. In general, this snowball sampling proved very effective, thus avoiding aimless and time-consuming search activities.

However, this approach has its downside. As people are more likely to provide leads to those who are similar to themselves, this limits the diversity of the sample. In order to minimize this drawback, the author limited the number of families that each channel brought to the research. The final sample was introduced through nine channels, and from each channel no more than five families were selected. It needs to be noted, however, that although these families were diverse in terms of their ages, occupations, and life trajectories, they represent only a part of the migrant population in Beijing. This study has therefore left out many other groups of successful migrant families. Moreover, given the small scale of the sample, however diverse, their life experiences may not be able to reflect the diversity of migrant businesspeople in Beijing. Hence, while the conclusions of this study allow for a better understanding of a number of cases, they might not be applicable to others. In this sense, this research is only another contribution to a deeper understanding of migrant issues in China. It makes no claims to universally applicable conclusions in the topics addressed.

The qualitative empirical study was conducted in Beijing in 2017. Abundant information pertaining to interviewees' economic and social lives was obtained from in-depth interviews with both husbands and wives and from direct observations on their business activities and working conditions. The conversations were taped and transcribed, and detailed field notes were made after each visit. These materials constituted the empirical evidence of this study.

The ages of the sample ranged from 28 to 52, with the majority concentrated in their thirties and forties, and a minority grouped in their late twenties (see Table 1). Their age distribution had some differences in comparison with that of rural migrants in Beijing as a whole. For example, rural migrants aged 16-25 accounted for about $11.4 \%$ of the total migrant population in Beijing (BSB 2017). In the sample, however, nobody fell into this group. Another significant difference was reflected in the 36-55 age group. The percentage of the sample in this group was about 18 points higher than that of

${ }^{2}$ The Beijing Bureau of Statistics (2017) regarded per capita disposable incomes above 105,425 yuan as the standard of high-income (top 20\%) in Beijing. As rural migrants have to pay education, housing and health care by themselves, they need much more money to maintain the same level of living standards as Beijing residents. For that reason, "successful migrants" were defined as people whose incomes doubled the official standard. 
Table 1 A comparison of age distributions between the sample and rural migrants in Beijing as a whole

\begin{tabular}{llllll}
\hline & $\begin{array}{l}\text { Age 16-25 } \\
(\%)\end{array}$ & $\begin{array}{l}\text { Age 26-30 } \\
(\%)\end{array}$ & $\begin{array}{l}\text { Age 31-35 } \\
(\%)\end{array}$ & $\begin{array}{l}\text { Age 36-55 } \\
(\%)\end{array}$ & $\begin{array}{l}\text { Age 56-70 } \\
(\%)\end{array}$ \\
\hline $\begin{array}{l}\text { Rural migrants in Beijing as a } \\
\text { whole }\end{array}$ & 11.4 & 18.7 & 16.8 & 47.4 & 5.7 \\
\begin{tabular}{l} 
The sample \\
\hline
\end{tabular} & - & 8.3 & 26.7 & 65.0 & - \\
\hline
\end{tabular}

Source: The 2017 Annual report of the Beijing Statistic Bureau (BSB 2017)

ordinary migrants (65\% in comparison with $47.4 \%)$. These differences suggest that, on the one hand, the establishment of businesses may need long-term involvement, and, on the other hand, wealthy migrants may be more likely to stay permanently in cities as compared to ordinary migrants.

It needs to be noted that the majority of the interviewees started their migrant life in their teens or twenties, and yet nearly one-fifth left home in their thirties. Their current ages alone therefore were insufficient to clarify their migration history given the large age gap. Those in their late twenties were not necessarily newcomers, while those in their forties were not necessarily more experienced. For instance, Mr. Yue came to Beijing for the first time when he was only 15 . Thus, he already had more than 13 years of business experience at the age of 28. By contrast, Mr. Zhao moved and had engaged in business for only 5 years, though he was already 37 years old at the time of the interview. The younger migrants usually had no farming experience. Most of them moved out of their villages as soon as they left school. The relatively older ones, however, were mostly former farmers, though some of them had become temporary workers or small businesspeople before moving to Beijing.

Constrained by their low educational attainment (at a mostly junior high school level), these families usually concentrated on businesses that did not need specialized skills, such as small commodities like timber, furniture, fruit, vegetables or seafood, or small services like car maintenance, transportation, or horticulture. Their businesses were all family managed, usually with a clear and gendered division of labor. In most instances, husbands were in charge of business and wives were cashiers in shops. In the cases where wives were full-time homemakers (seven women stayed at home for a variety of reasons), usually their close kin would take cashier positions.

The interviewees were usually engaged in business related to their home town specialties. For example, the Yus and the Wens came from "the home of horticulture" (Jiangsu province) and "the home of green tea" (Zhejiang province), respectively, and thus they entered the horticultural and the tea business, respectively. Likewise, the home regions of the Yangs and the Xiaos abound in vegetables and wood. These two families thus took up the vegetable and the timber businesses, respectively. The advantage of access to local specialties made rural migrants from a certain area tend to dominate a certain business domain, to the extent that their local dialect could become a common language in a particular market.

Apart from local specialties, social networks also played an important role in channeling the families to a certain occupation. Except for a few pioneers, these families all entered a particular business by following their contacts. Moreover, as a consequence of a distrust of outsiders, their businesses all remained family managed, and key positions were always occupied by their close kin, such as siblings, uncles, nephews, or nieces. 
This intense nepotism led to not only lengthy chain migration but also a gathering of kin and fellow villagers in their businesses. Thus, despite their long-range mobility, they were still deeply embedded in their old social networks. While these old ties remained an important source of social support, they might also have impeded their social integration into the new urban community. The following sections will investigate their contacts with kin, friends, and locals.

\section{Contact with kin}

Kinship derives from blood or marital ties and involves a long history and strong emotions. These natures make it quite "special" in comparison with other types of relationships (Devine 1992, p. 62; Finch 1989). The importance of kinship ties for one's social life has been demonstrated by numerous studies (Anwar 2002; Bott 2002; Wellman $2002 \mathrm{a}, \mathrm{b}, \mathrm{c})$. It has been widely agreed that kin remain one of the most important sources of companionship and mutual support. Of all the sorts of kinship ties, parentchild ties are the most close and supportive. Siblings are supportive to a lesser degree than parent-child ties. Other relatives, such as cousins, aunts, and nephews, however, are usually not very helpful (Bott 2002; Wellman 2002a). This seemed to be the case for the interviewees as well, though their geographical and social mobility did influence their relationships with kin in some ways. This section examines the relationships of the interviewees with their parents, siblings, and extended kin.

\section{Parents}

As mentioned, parent-child ties are regarded as the most intimate and supportive in one's social life. As Wellman (2002c, p. 94) put it,

The bond between parent and adult child is the most supportive of all intimate and active ties, providing high levels of both material and emotional support. Such ties are so broadly supportive that weaker, but still active, relations are usually almost as supportive as intimate relations.

Indeed, the interviewees all considered their relationships with parents as the most close and supportive. They kept intense contact and provided each other with considerable emotional and material support, regardless of physical distance. Yet, it needs to be noted that the relationships of the interviewees with their paternal and maternal parents were different in terms of the degree of their intimacy, their obligations, and their mutual support of each other. In line with China's traditional patrilineal family principles (Fei 1985), they usually involved much more mutual support with paternal parents than with maternal parents. Given these significant differences, these two pairs of relationships are explored below.

The particular intimacy of the interviewees with their paternal parents is largely a result of the traditional Confucian culture. ${ }^{3}$ Intense family ties are deeply ingrained in the minds of the Chinese people. The filial piety of sons toward parents is especially emphasized (Fei

\footnotetext{
${ }^{3}$ The obligations of sons towards parents are extremely emphasized in Chinese culture. As Fukuyama (1995, pp. 85-86) explained, Sons have the duty to defer, even as adults, to their parents' wishes, to support them economically when they are old, to worship their spirits once they are dead, and to keep alive a family line that can be traced backward through generations of ancestors.
} 
1985; Fukuyama 1995). Although paternal authority has been declining in contemporary China (Yan 2003), the traditional patrilineal principles remained influential among the interviewees. Apart from three women who were in conflict with their parents-in-law, the others all maintained very strong relations with their paternal parents. The ties were so intimate that in many cases their paternal parents were regarded as members of their nuclear family, and there were no clear divisions of ownership- "belonging to me" versus "belonging to my parents" - in terms of family property. It was very common that parents would present their lifetime savings to their sons without asking for a share in their businesses.

The mobility of the interviewees did not undermine their intimacy with their parents. For instance, before migration, they usually lived either together with or very close to their paternal parents. This form of habitation was very convenient for them to help or look after each other. After the interviewees migrated and settled down in Beijing, more than half of the families (16 families) also moved their parents to Beijing. Mr. Fang explained:

Nowadays, I have the economic strength to ensure my parents a comfortable life. I would like them to enjoy a peaceful, quiet and easy life in their old age in Beijing. They have done so much for me. I just could not leave them in the village when I became wealthy. This is what a son should do ... Moreover, they feel very lonely at home and are very happy to help us look after the children and the home.

These parents were usually regarded as the most fortunate people in the village because of their dutiful and capable children. Through their good conduct, the sons also established good reputations for themselves in their home towns. The support, however, was usually mutual: while the interviewees were providing their parents an easy life, their parents reciprocated. In many cases, their parents engaged in domestic tasks like childcare, cooking, washing, and cleaning. Such assistance relieved the interviewees from domestic work, enabling them to devote most of their time to their businesses. As Mrs. Shi stated,

My younger daughter is 7 years old, and my son is only 3 years old. They both need intensive care, but we are too busy to look after them ... I am very happy that my parents-in-law want to take care of them ... They are so nice. They do much better than me in terms of childcare. I no longer worry about the children, even if I don't see them for several days.

More often than not, domestic tasks were performed by mothers. Fathers usually engaged in business and worked as watchdogs for the family property. For example, in the sample, ten fathers were in charge of storehouses or logistics, where embezzlement was believed more likely to occur and thus one's own people were needed.

Those who left their paternal parents behind also fulfilled their filial obligations. In addition to financial support, these families often built their parents a house in their village. Equally, their parents were also the most important source of support for them. Taking the Wus' case as an example, they did business in Beijing, but their older daughter needed to get her high school education in their home town. Mr. Wu's parents voluntarily took the responsibility to look after their granddaughter. Similarly, the 
Suns also left their twin daughters in the care of their paternal parents in their village. Thus, despite living far away from each other, this significant physical distance did not weaken their close relationships with their parents. This is consistent with what has been found elsewhere. That is, the intimacy of parent-child ties is not necessarily undermined by geographical distance. There is no simple relationship between the contact frequency and the nature of a relationship (Devine 1992; Wellman 2002b).

The relationships of the interviewees with maternal parents were not so close, however, with less intense mutual support between the two sides. Few maternal parents would give their lifetime savings to their daughter's family, although they might help them to raise money. Likewise, the interviewees felt no obligation to fully support their maternal parents, though they would provide some assistance. Nevertheless, this is not to say that the relationships between the two sides were not intimate. They maintained close contact with each other as well, but too much financial or material involvement was generally regarded as improper, especially if maternal parents had their own sons. For instance, paternal parents usually fulfilled the duty of childcare. The interviewees all took this for granted. As Mrs. Yue felt,

I cannot ask my parents to look after my son. They have their own grandson (their son's son) to care for ... In addition, I don't want to make my brother and sister-inlaw unhappy. Anyway, this is my parents-in-law's bound duty.

Similar to Mrs. Yue, many interviewees considered that they would turn to their maternal parents for such help only if their paternal parents were no longer alive. This is quite different from what has been found in urban areas, where mother-daughter ties were found to be especially supportive because of their shared concerns about grandchildren and domestic responsibilities (Xu 2015; Li 2017).

This by no means suggests, however, that women were becoming estranged from their parents. Rather, the niang jia (a married woman's natal family) was always the most powerful backing for these women. What is at stake here is that, in the Chinese case, obligations and rights were especially emphasized on the patrilineal family side. This inclination seemed so significant that it affected many aspects of the life of the interviewees. Taking their residential patterns as an example, while 16 families moved their paternal parents out of their villages, only one family moved their maternal mother to Beijing (their maternal father and paternal parents had already passed away.). All the others left their maternal parents behind. The interviewees usually took full responsibility toward their maternal parents if the sons of their maternal parents failed in their filial duties.

In spite of the varying intimacy between the two kinds of relationships, however, it is very clear that the economic success and considerable geographical mobility of the interviewees did not affect their close ties with their parents. As Bott (2002, p. 365) maintains, however mobile a person is, one still feels an obligation to maintain contact with one's parents. In the Chinese case, this seemed to be taken to an extraordinary degree: the interviewees regarded their obligations toward parents as compulsory, considering that their parents maintained an important position in their family. In addition, as the most successful figure in their family, the interviewees usually fulfilled these major obligations or even undertook nearly all responsibility for their parents. In this sense, their 
economic success actually strengthened rather than weakened their relationships with their parents. Then, in what way did their mobility influence their relationships with other kin, such as siblings and extended kin? All of this will be the main topic of the next two subsections.

\section{Siblings}

Like the parent relationships, the economic success of the interviewed migrants did not isolate them from their siblings as well. Their siblings constituted a particularly important source of social support for them in their new places of residence. What was special was that while the intense financial and practical involvement between the two parties strengthened their ties and obligations toward each other, it also tended to undermine the equality of their relationships. This subsection is mainly concerned with these issues, with particular attention paid to the asymmetric dimension of the sibling relationships.

As already mentioned, the interviewees usually maintained close contact with their siblings. The overwhelming majority of them considered their siblings very reliable and supportive in times of need, especially upon encountering big issues or crises. Most of them engaged in intense service exchange with their siblings and provided considerable support and companionship to one another. This involvement of substantial support significantly strengthened their bonds and obligations to each other. For instance, nearly all of the interviewees brought their siblings (or the children of their siblings, if their siblings were too old to move) to Beijing. In both instances, their siblings felt indebted, and thus were ready to provide considerable support that they might be reluctant to give normally. The three families who left their children in the care of their siblings are examples of this. These families all had children in high school. As the couples were too busy to go home, they all left their children to their siblings. This kind of substantial help is common between parents and children, but very unusual among siblings. Given their siblings' feelings of gratitude, however, their siblings were very happy to do them this big favor. As Mrs. Liu stated,

My son needed to study in our home town during high school, but we were too busy to go home with him ... My parents-in-law also live in Beijing, helping us to look after the home and the other three children. My husband's older sister then voluntarily took care and custody of our son ... I'm not very worried about him now. He gets along well with his aunt and uncle.

In the Lius' case, they helped their nephew and niece to move out of the village, and Mr. Liu's sister in turn helped them to look after their son. Despite the clear reciprocal nature, their mutual support did enhance their obligations toward each other.

Apart from domestic matters, the interviewees also involved their siblings in a number of business dealings. This further strengthened their ties. For example, in some cases, siblings were partners and had to work together; in other cases, siblings were engaged in the same occupations, and they needed to work together to compete in the market. Sometimes, siblings established manufacturer-agent ties. They had to fully cooperate because of their shared livelihoods. Moreover, siblings were also an important 
source of business information and financial loans. Such forthcoming dealings intensified their interactions with each other.

Another likely more important factor contributing to their intimacy was their migration. As has been shown in the literature, migrants tend to maintain close contact with siblings in their new destinations, and they are more likely to live nearby and provide companionship and support to one another (Devine 1992, p. 62; Goldthorpe et al. 1987). This was especially the case for interviewees who had experienced long-range geographical mobility and were living in an environment which they perceived to be unfriendly. They usually lived in the same neighborhood with their siblings and engaged in considerable visiting and service exchanges with each other. As Mrs. Lin stated,

We live in the same neighborhood with my brothers and sisters-in-law. It's very convenient for us to look after each other ... For example, we need to send the children to school in the morning and collect them again in the evening every day. It is really highly time consuming ... We then decided to take this duty in turn ... We help each other to look after the children when someone is busy ... My nieces and nephew often sleep at my home, as does my son at their homes ... It is inappropriate to bother others with such matters, but we are from the same family. We ought to help each other.

This form of habitation enabled them to provide a high level of mutual support. Those who had moved their parents to Beijing particularly preferred to live in close proximity. Parents and children then could see and look after each other conveniently.

Nevertheless, despite maintaining close contact, the interviewees all agreed that their relationships with their siblings were less intimate than with their parents on both the paternal and maternal sides. This confirms previous findings that, namely, sibling ties remain an important source of companionship and support, second only to parent-child ties (Devine 1992, p. 57; Wellman 2002c). Furthermore, unlike with parents, sibling relationships tended to be largely unequal due to the asymmetrical contributions between the two sides. In other words, although their mobility did not undermine their intimacy with siblings, it did tend to change the nature or power structure of their relationships. As mentioned, the interviewees usually played an important role in helping their siblings to leave their homes and establish themselves smoothly in the city. Nevertheless, siblings often could not provide them with help in the form of business opportunities or large loans. The asymmetrical contributions of the two sides then gradually placed the "benefactors" in positions of superiority in relation to the "beneficiaries." Asymmetrical relationships then began to take shape when the two parties both felt the need for the "beneficiary" to show respect to the "benefactor." The words of Mr. Zhang, a fruit wholesaler who owns ten private shops in Beijing, were a good illustration of this point:

My four siblings - my older brother, my two younger brothers and my sister-all followed me to Beijing. I didn't want them to get involved in my business, so I helped each of them to start their own ... I rented them my shops at a lower price and offered them preferential prices in goods ... All of them are millionaires now ... 
I do not see them too often, but they must visit me on the New Year or other festivals. This is necessary of them.

In this case, the relationships between Mr. Zhang and his siblings were obviously asymmetrical. Mr. Zhang expected that his relatives should visit him on festivals. This seems to exceed the normal expectations held between siblings. On the other hand, the fact that his siblings were willing to visit him suggested that they accepted this unequal relationship.

This type of asymmetrical sibling relationship was very common among the interviewees. Mr. Zhu gave the following explanation:

This is quite natural ... What would you do if your brother buys a bigger home for you and moves you to a better neighborhood? If you usually have two dishes for dinner, you might prepare a sumptuous feast when he comes ... If all family members have to rely on you to make a living, your position in your family certainly moves upwards. Nobody will go against your will. On some occasions, even your parents will respect and flatter you. You will feel very uncomfortable sometimes, but you will get used to it. Anyway, you pay and you gain.

These businesspeople were situated in a "structurally central intimates" position, as coined by Wellman (2002b, p. 409). These types of people, as Wellman suggests, are more likely to provide help, and simultaneously it is exactly their ability to provide help that have made them central. Indeed, the interviewees were not only the main source of financial support but also an important source of business opportunities for their siblings. In Mr. Zhang's case, for instance, his support was of the utmost importance for his siblings leaving the village and achieving success in Beijing. What Wellman neglects is that while these "structurally central intimates" provide extra support to others, they also expect others to show respect to them, be they kin or friends. A hierarchical relationship system then forms, with the most powerful figure in the center, surrounded by those who are indebted. This point is best elaborated by Blau (1964) in his exchange theory. He maintains that in a group, those who need something from someone else but have nothing comparable to offer tend to subordinate themselves to their benefactors. Those best able to reward gradually emerge as leaders, and the group is then "differentiated" (Ritzer and Goodman 2003, pp. 412-413).

To sum up, the geographic and social mobility of the interviewees did not weaken their relationships with siblings. They usually kept close contact with siblings and provided considerable companionship and support to each other. Nevertheless, while the intense exchange of help or services strengthened their bonds and obligations on the one hand, it also tended to make their relationships unequal. These findings also seem applicable to their relationships with extended kin in some ways.

\section{Extended kin}

The relationships of the interviewees with their extended kin, such as cousins, nephews, aunts, and uncles, were not very close. They had little feelings of obligation toward such kin and usually engaged in few service exchanges with them. Research does not suggest, however, that mobility is the cause of these relatively distant relations 
established with extended kin. This study provides no evidence to suggest that their intimacy with extended kin changed significantly in comparison with their pre-mobility period. In other words, the less frequent interaction between the two sides was largely due to their low-obligation involvement or physical distance rather than social distance.

More often than not, relationships with extended kin were sustained through elders. This was especially the case when considerable support was involved. Taking Mr. Hu's case as an example, Mr. Hu wanted to borrow some money from his uncle as starting capital. Although he had been working in his uncle's business for several years and saw his uncle almost on a daily basis, it was his father who asked for the loan. Mr. $\mathrm{Hu}$ explained:

My uncle helped me for my father's sake and not for mine. He would like to support my father and aid him voluntarily, but he has no duty to support me ... They are brothers, but we just have an uncle-nephew relationship ... Their relationship is much closer, even though they haven't seen each other for years ... It was simply not appropriate to ask for the loan myself. How could I go around my father on such an important matter?

Indeed, as a Chinese saying goes, "An extra tier in relationships adds an extra tier of separation." Parents were more intimate with their extended kin. Therefore, it was much better for them to act as intermediaries, especially when substantial support was involved.

Parents also played an important role in the regrouping and solidarity of the large number of relatives in Beijing. The Shis are a case in point. One of Mr. Shi's cousins wanted a job in Beijing. He did not ask Mr. Shi directly; instead, he asked Mr. Shi's father through his own father. Mr. Shi's father felt it was his duty to help his nephew move out of his village, so he got him a job in Mr. Shi's firm. Under such conditions, Mr. Shi could only accept the decision. He complained:

My father decided this for himself. I had no knowledge of this even though my cousin had already arrived in Beijing ... My father asked me to find a job for him, but at that time there was no vacancy in my firm. My father said, "you can fire others or find him a job elsewhere. I promised your younger uncle that I will take care of his only son in Beijing. You must do it." I had no choice but to keep him in my firm.

Not only his father, Mr. Shi's mother also recommended her close kin to him. On some occasions, Mr. Shi had to be very cautious in order not to hurt the feelings of his parents. In addition to direct recommendations, his parents also regularly organized family gatherings during various festivals at home. These activities on the one hand strengthened their ties with extended kin and, on the other hand, also put Mr. Shi in a passive position, for he was often "forced" into relationships with those whom he did not want to contact. The involuntary nature of these relationships has been noted by Wellman in his family study. Wellman (2002a:103) remarked:

In practice, many ties are with network members whom one does not like and with whom one would not voluntarily form a twosome. Such ties are involuntary in that 
they come as part of the network membership package. They may be ties to persons who must be dealt with at work or in the neighborhood. They may be part of a solidary kinship group or friendship circle, or they may be patron-client ties.

Yet, this is not to say that the interviewees always played a passive role in their interactions with extended kin. In many instances, they were also very active in pursuing the support or cooperation of these relatives. Low-trust toward strangers made the interviewees prefer relatives to outsiders. However distant extended kin are, they are much more reliable than outsiders. Therefore, in case of personnel shortages, these businesspeople usually chose their relatives in preference to others. Moreover, they were more likely to place their kin in important positions. In so doing, they could not only ensure a stable and loyal workforce but also put their relatives in debt by offering them a job in the city.

Nevertheless, generally speaking, these extended kin were less supportive than parents and siblings. Sometimes, they even became a burden because of their sheer number. Some interviewees expressed frankly that they often deliberately avoided seeking assistance from extended kin. As Mr. Mu explained,

We have about 50-60 kin in Beijing. If you ask one of them a favor, all of the others will soon know about it. A small thing will be made into an event, so sometimes I would rather ask friends than resort to relatives.

Furthermore, given the large number kin involved, it was impossible to stay in contact with them all. Apart from those who worked in their own firms or those with whom they had business dealings, the interviewees usually did not keep in close touch with other extended kin. They did not see each other too much during their daily lives, except on occasions like weddings, the birthdays of family elders or various festivals. Mostly, it was through their elders that they had knowledge of the circumstances of their kin.

So far, the sociability of the interviewees with their parents, siblings, and extended kin has been investigated. As Goldthorpe et al. (1987) observed in Britain, there are also grounds to assert that, in China, social mobility itself has no necessary disruptive consequences on kinship relations. The interviewees largely maintained similar social patterns with their kin as they did during their pre-mobility period. Although there were no effects on their relationships with their parents, the economic success of the interviewees did lead to asymmetric relationships with siblings and extended kin due to the fact that these relatives usually relied on them to migrate or obtain substantial support. These findings suggest that although social mobility is not inimical to kinship maintenance, it is likely to change the nature-or perhaps more appropriately, the power structure-of kinship relations, especially for those with intense practical involvement. The next issue to examine, then, is the sociability of the interviewees with their friends.

\section{Contact with friends}

The geographic mobility and economic success of the interviewees did not clearly disrupt kin relationships. Immediate kin remained the most supportive in helping the interviewees achieve and maintain settled lives in Beijing. Then how did social mobility 
affect their relationships with friends? Did they tend to sustain old ties after they became successful?

The friends of the interviewees can be divided into two types: a small set of confidants, or close friends, and a relatively large number of ordinary friends. The former was mainly made up of friends who knew each other for years from childhood, school, business or the army, and who enjoyed similar economic conditions and social statuses to date. The latter was mainly made up of migrant businesspeople, largely acquaintances that were developed through doing business or in social contexts like gatherings of friends or neighborhoods in the market. These two types of friends played different roles in the social and economic lives of the interviewees. Close friends, similar to intimate kin, usually could be counted on during both trivial matters and in times of crisis. They were in general "as likely as siblings to provide support and much more likely to do so than extended kin" (Wellman 2002c, p. 96). Ordinary friends (or business friends), on the contrary, were less helpful in this respect. These friends mainly consisted of businesspeople who shared a similar background with the interviewees. Usually, fellow villagers made up nearly half of these friends. ${ }^{4}$ There are two possible explanations for this. First, a common origin can significantly reduce feelings of distance and facilitate sociability, especially for newcomers who usually feel rootless and long for familiar things (Ma and Xiang 1998, p. 550). Second, as migrants from the same place tend to concentrate on a particular trade, this gives rise to the congregation of fellow villagers in a particular business. The interviewees then had more opportunities to socialize with such villagers.

These ordinary friends were in general not a source of emotional or material support. Some interviewees even considered that they were not real friends. Mr. Wu, for example, felt, "There are no real friends in business. Nobody will help you sincerely. People always compete in the pursuit of profit." Nevertheless, these friends were very important in terms of providing diverse resources and seeking access to new social circles. A large circle of business friends were particularly important for these migrants to achieve economic success in the city. Usually, it was these friends to whom they devoted most of their time.

In spite of the significant differences, these two types of friendships had something in common: both of them were not fixed. The interviewees all considered that their friendship circles had changed significantly in comparison with the past. Most stated that they no longer kept in touch with about $70-80 \%$ of their old friends. This variation of friendship ties has been widely noted in network literature. Barnes (2002, p. 315), for instance, maintains that the field of friendship has no boundaries, since "new ties are continually being formed and old links [are] broken or put into indefinite cold storage." In explaining this phenomenon, some scholars (Wellman 2002a, pp. 103-104) argue:

[T] here are finite limits to the number and intensity of ties that an individual can maintain (and ... most individuals are near these limits). Consequently, most people cannot add many new ties (or add new strands to existing ties) without giving up some of their existing ties.

\footnotetext{
${ }^{4}$ It needs to be noted that "fellow villagers" here not only refers to people coming from the same village or the same town, but also refers to people from the same region or even the same province. The boundaries for fellow villagers are very flexible. Common identification might exist on each level of common origin like the village, town, region or province (Zhang 2001).
} 
Indeed, people may give up ties due to finite limits. Nevertheless, this study suggests that geographic, occupational, and social mobility may play a more important role in this regard. That is, the variation of friendship ties is more likely caused by mobility in various spheres than by the finite number of ties that one can bear. Among the sorts of mobility, geographic and occupational mobility produce the most instant results. For instance, the interviewees who had experienced long-range geographic mobility usually did not maintain contact with old friends in their home towns. Most of them simply considered this inevitable. As Mr. Xiao explained,

If you farm at home, you will only get to know peasants. If you work in the city, you will socialize with migrant workers. When you start to do business, you will mainly deal with businessmen. Your social circles of course will change accordingly. This is quite natural. Birds of different feathers do not flock together ... Your relationships with old friends will gradually fade away if you do not contact each other for a long while.

Under such circumstances, both sides lost interest in maintaining their relationships. The old ties then ended gradually. What this research is particularly interested in is how in many instances the end of old ties was caused by social mobility. That is, they were cut off deliberately because of their uselessness or status inequality produced by asymmetric mobility. Mr. Zhu elaborated on this issue:

The majority of our friends are people similar to us. A few do a little bit better or poorer than we do. Those old friends who do not do well are almost all forgotten ... I feel that friendships are more likely to become broken under three circumstances. The first is when some friends wrong you, but you have to maintain the relationship due to a variety of reasons. You will naturally cut off your ties when they are no longer useful ... You will say, "Oh, I am busy. I will call you later." After several attempts, they won't contact you any more ... The second circumstance concerns relationships mainly based on material interests. This kind of friendship has little emotional involvement. When they change positions or you no longer need their resources, the friendships end ... The third circumstance is when the gap between you and your friend is too significant. They feel a bit inferior and are unwilling to keep in touch with you. They may shun you or decline you, even if you actively contact them. Gradually, these ties will fade away.

The three circumstances that Mr. Zhu described could be categorized into two types. One was ordinary friends who were given up due to uselessness. In this instance, it was usually the interviewees who took the initiative to cut off ties. The other was close friends who drifted apart because of unequal status. In this instance, it was usually their friends who gave up the friendship. While taking the first instance for granted, the interviewees usually felt confused about the second one. As Mrs. Wu stated,

I do not know why some old friends no longer pop in for a chat. In the past, they always felt free to knock at the door any time. Nothing wrong happened between us. I feel a little bit strange. 
Most interviewees had similar experiences. Mr. Shi attributed this to a complex psychological feeling on the non-mobile side:

This is always the case for rural people. They always think: we were the same in the past. Now you are rich and I am poor, but I do not want to fawn on you ... They feel a sense of imbalance and do not know how to conduct themselves appropriately when socializing with you. For example, should they act as an old friend or as a subordinate? Both seem inappropriate.

To be sure, people may experience subtle feelings when those who were once on a par with them undergo a meteoric rise. It appears that one's social mobility expands not only social distance but also interpersonal distance with old ties. Close friends become estranged. Besides the psychological element, practical difficulties, such as financial constraints on the poor side, also play a big part in the estrangement of friends. Here, Mr. Huo's experience provides a good example:

I had a buddy when I served in the army. We used to get along very well ... We both engaged in business in Beijing after retiring from the army. His business is not doing well, unfortunately-he is a peddler in fact ... He used to visit me frequently, but he no longer stops by any more now ... One time he even declined me when I knocked on his door, wanting to drive him to a friend's gathering ... A once common friend of us said to me, "You better leave him alone if you want to do him good. He is struggling in life. How can he have extra money to spend on such entertainment?" ... Indeed, you always need to pay something for a gathering, for example, food, clothes or travelling expenses, etc. This would be a big burden on him. Sometimes we would pay the entertainment expenses in turn. He certainly would not come if he could not afford the cost ... He might also feel uncomfortable when seeing our spending habits, I guess. I considered our friend's words quite apt and did not "bother" my old friend any more.

This story more or less demonstrates Bourdieu's proposition; different consumption patterns tend to distinguish people into different groups. According to Bourdieu (1984, p. 471), consumption patterns largely indicate one's economic and social position in society. These different conditions of existence then give rise to the formation of a "sense of one's place," thereby leading one to "exclude oneself from the goods, persons, places and so forth from which one is excluded."

It can be seen that, however varied the reasons, they seem to lead to the same consequence: people are more likely to hang together with those who share a similar status. As the stories of the interviewees demonstrate, individuals tend to give up friends who cannot move forward at the same pace. Consequently, friendship circles that emerge in the process of voluntary interaction are more likely to comprise people of approximately equal status. From this point of view, one's friendship circles largely indicate one's social position in society, and accordingly they are likely to change alongside the change of one's social position. Indeed, as elaborated above, the friendship circles of the interviewees changed significantly as they moved upwards. While they were building up new ties, their old ties that were unable to keep pace were largely left behind. 
This seems to suggest that the change of one's social circles is a likely signal of one's social mobility and vice versa, i.e., one's social mobility is also likely to give rise to a change of one's social circles.

\section{Contact with locals}

So far, there are grounds to assert that the economic success of the migrants was more likely to strengthen their bonds with kin, while it tended to weaken their ties with friends who lagged behind. The issue now is to explore their interactions with locals. Typically, "locals" are people who are officially registered in Beijing. Due to their different occupations, the interviewees had very little opportunity to socialize with people in other groups. Kin and migrant businesspeople made up their main social circles. Nevertheless, unlike poor migrants who usually concentrated together in the suburbs (Xiang 2005), the businesspeople in the sample showed no particular tendency to congregate with other migrants in terms of their place of residence, except with their immediate kin. They were scattered throughout urban neighborhoods, mixing with local Beijing residents. It appeared that these businesspeople had more opportunities to come to know the locals in their daily routines than ordinary migrants. ${ }^{5}$ Then how did they socialize with their urban neighbors? Did their economic success facilitate their integration into the local host communities?

China's urban neighborhoods have changed a great deal since the country's economic reforms. In the past, employers always built and assigned residences to staff and workers. Consequently, a particular neighborhood would usually be occupied by the same staff of one particular work unit (Ma 2015). Commercial housing began to emerge from the end of the 1980s. Neighborhoods that mixed people from different work units and occupations then appeared. With the mushrooming of a huge number of commercial housing estates, this type of neighborhood is becoming increasingly ubiquitous in urban China. Such neighborhoods are usually occupied by people who have different occupations but are relatively homogeneous with regard to income (Ma 2015; Song 2017).

The economic strength of the interviewees enabled them to buy homes in such neighborhoods. For instance, 20 out of the 30 families owned at least one house in Beijing. Among them, 13 families lived in their own homes; the other seven all rented their homes and lived in their shop or factory. The ten families without a house in Beijing either lived in their shop (two families) or in residences rented from local people (eight families). For those who lived in shops or factories, neighbors largely meant migrant businesspeople or migrant workers. These families apparently had little opportunity to interact with locals. The discussion of this section therefore mainly focuses on the 21 families who lived in urban neighborhoods, including both those living in rental properties and those living in their own homes.

It was very striking that despite living in urban neighborhoods, the 21 families all reported that they had very little contact with their neighbors during their everyday lives. It seemed that the closeness of residence did not shorten their interpersonal distance with the locals at all. These interviewees did not know who their neighbors were and

\footnotetext{
${ }^{5}$ As neighborhoods were the main contexts for which these migrants could come across local residents, this section mainly focuses on the sociability of the interviewees with their urban neighbors.
} 
what occupations they engaged in, although some of them had lived in their present home for years. Most interviewees described their relationships with neighbors as distant or even cold, considering that they were neither friends nor enemies. Some interviewees simply took this kind of distant neighbor relationship for granted. As Mr. Xiao felt, "This is what urban life is. In urban neighborhoods, nobody cares about you, and you do not need to care about others either." This might be true in contemporary urban China. Most urban neighborhoods now are no longer inhabited by people from the same work unit. Relationships between neighbors therefore could be more distant than in the past. Nevertheless, even if this is also the case among locals, it still cannot be used readily to explain the migrants' case. This is because it cannot explain why the six families who lived in suburban villages, where traditional close relationships among neighbors are still maintained, still had little contact with their neighbors. On the contrary, these interviewees expressed the strongest feelings of dislike for the locals. As Mrs. Sun complained,

We do not keep in touch with our neighbors. We even do not say hello to each other. I feel they are xenophobic ... The way that they view outsiders is completely problematic. They always feel superior as locals. But what's unusual about that? I don't see where their superiority comes from ... We are just not the same kind of person. I think so, and so do they. Anyway, we are different. I think this is the point ... We just ignore each other's existence. They have their lives and we have ours ... This is totally different from our lives in our village, where the relationships between neighbors are always intimate.

The overwhelming majority of the interviewees expressed similar feelings as Mrs. Sun. Most of them strongly disliked locals. In their discussions, locals were always portrayed as indolent, incompetent, xenophobic, loving comfort, and hating work; migrants, on the contrary, were hardworking, honest, steady, and reliable. Whenever the locals were mentioned, they complained or blamed their laziness and superior attitude. Otherwise, they stressed the differences between them, such as their different kinds of jobs, different backgrounds, and different social perspectives. The interviewees used the sentence, "They are different from us," most frequently when referring to them. As Mr. Mu stated,

We seldom make contact with the locals. Unlike us, they are usually engaged in paid work. A few of them also do business, but they socialize with their locals and we socialize with our outsiders ... Of course we are different. They have stable jobs and are entitled to various benefits, while our undertakings are risky ... Yes, we also live well-to-do lives, but you need to see this in the context. Do you know how hard we work and how much we suffer? Do the locals need to work so hard? ... The good jobs are open only to them. How can you talk about fairness under such conditions?

Such feelings without doubt reinforced the estrangement between the two sides, thus impeding their relationships. Therefore, despite living in close proximity-sometimes literally next door-they remained strangers. This fact supports Bott's (2002, p. 359) argument that suggests that the neighborhood is not a solid organization but a network. 
What really matters is "the network of actual social relationships" one maintains, and not the local area in which one lives. In the Chinese case, it seems that the markets where these migrants worked replaced their neighborhoods, becoming their practical communities. They spent most of their time in the markets where they not only engaged in business but also made friends. In this sense, these markets could be likened to a village. The "villagers" knew each other quite well, such as knowing who was rich and who was poor, who was well-behaved and who was ill-behaved, and who were in conflict and who were intimate together. They contacted frequently and often engaged in many small service exchanges. For example, those who got along well often borrowed small things from each other or helped to keep an eye on each other's businesses when they were temporarily absent. These neighbors were also an important source of companionship. They always chatted or played cards. Some became good friends; some even became couples. Mr. and Mrs. Yue, for example, met each other in a market that they had once worked in.

These markets also attracted the five full-time housewives who stayed at home for childcare. Despite having plenty of time, none of the housewives developed intimate relationships with their urban neighbors. For these women, their immediate kin who lived in the same neighborhoods were the most important sources of emotional and practical support. When free from both domestic tasks and the company of kin, they preferred to go to their shops, chatting with their market neighbors. Mrs. Wei stated:

We live in the same neighborhood with my husband's sister and brother-in-law. I get along well with my sister-in-law ... We meet nearly every day and always go shopping together or help each other to look after the children ... I do not see much of my other neighbors. Sometimes I meet them in the shop or street, but we don't chat a lot. I don't know why. I just feel estranged from them and want to keep a distance ... When I have nothing to do at home, I will go to our shop and have a chat with the workers or shop neighbors. It is very interesting to hear them talk about their work or anecdotes from their home towns. I really enjoy the time spent with them.

As a consequence, these housewives were usually much more familiar with their market neighbors than with their real neighbors. It seemed that like their husbands they were attached to the markets far more than to the neighborhoods where they lived, though they did not work outside.

The familiarity of the interviewees with their market neighbors contrasted sharply with their distant relationships with their urban neighbors. Bott (2002, p. 362) believes that "localized networks are most likely to develop in areas where the local inhabitants feel that they are socially similar to one another, that they belong to the same social class, whatever their definition of class may be." Apparently, in the Chinese case, these businesspeople considered themselves socially similar to their market neighbors and not to their urban neighbors. They always described their market neighbors as people who shared similar attributes with themselves. This sense of belonging enabled them to build up ties on an equal and voluntary basis. Of course, this is not to say that their relationships with market neighbors were solid. Instead, most of these ties were given up when neighbors moved out of a market. Nevertheless, this variation did not affect their willingness to socialize with each other. There were no feelings of estrangement among 
them, regardless of whether they were good friends or were in conflict due to competition or other trivial matters. All of this contrasted significantly with their distant feelings about their urban neighbors. This might explain why the housewives would rather go chat in the markets than with their neighbors who lived nearby. It seemed that for these migrants the neighborhoods were merely a place where they slept, while the markets were the places where they actually lived.

In general, it has been found that the interviewees had little contact with the locals in Beijing. Few of them developed genuine relationships with their urban neighbors, no matter whether they lived in their own homes or in rental properties. This is consistent with what has been found by other researchers (Wang et al. 2016; Xiang 2005; Yue et al. 2013). Xiang's (2005) and Yue et al.'s (2013) research, for instance, both showed that in spite of living in the same neighborhood for years, migrants and locals largely lived in two different worlds and had little interaction with each other. These facts demonstrate that the economic success of rural migrants does little to facilitate their integration into the local host communities. In addition to different occupations and backgrounds, local discrimination against migrants also played a big part in the estrangement of the two parties. It appears that the status system established in the prereform era still remains influential in Chinese people's thinking. Urbanites, who held superior positions at urban-biased institutions for decades, seem to have already internalized this sense of superiority and have simply taken it for granted. Under such conditions, it remains difficult for rural migrants to be fully accepted by urban society.

This does not mean, however, that these migrants were more likely to suffer social isolation. Instead, they formed strong and supportive social networks in their new environment. Owing to the presence of numerous migrant businesspeople in Beijing, they had many opportunities to associate with people in similar positions. As Goldthorpe et al. (1987, p. 200) argued in their British study in this sphere,

It is not, or not necessarily, a problem of gaining acceptance, as a conspicuous outsider, into established social circles but rather, one may suppose, a problem not essentially different from that facing the stable individual - that is to say, one of forming relationships with, so to speak, his own kind, whom he can find about him in some number.

For these businesspeople, their markets replaced their neighborhoods, becoming their actual communities. Thus, despite being rejected by urban residents, they encountered little difficulty in social adaptation.

\section{Conclusion and discussion}

This paper explored the social lives of interviewees in Beijing. Their relationships with kin, friends, and locals were investigated. It has been shown that the economic success of the interviewees did not estrange them from kin but rather strengthened their ties and obligations toward each other. Their mode of association still followed the principle of chaxu geju. Among the various kinship ties, immediate kin like parents and siblings were the most close and supportive. They remained the most important sources of emotional and practical support for the interviewees. Other relatives, such as cousins, aunts, or nephews, were less helpful. Usually, it was through elders that they 
sustained contact with each other. Nevertheless, despite no disruptive effects, the mobility of the interviewees did influence their kinship relationships in some aspects. For example, their relationships with siblings and extended kin tended to be largely unequal due to the fact that these kin usually relied on them to obtain substantial support. This confirms other scholars' arguments that suggest that unequal power and dependency leads to imbalances in relationships (Ritzer and Goodman 2003, p. 418).

Unlike their stable relationships with kin, their relationships with friends tended to change along with changes to their economic and social positions. Old friends who could not keep pace economically were usually given up. In this process, geographic, occupational, and social mobility all played important roles. Some ties were ended because of physical distance, and some were cut deliberately because of social or interpersonal distance. The friendship circles emerging from such voluntary interactions therefore usually consisted of people of similar status. This fact strongly supports the homophily or "like-me" principle. That is, social interactions tend to take place among people with similar attributes (Bottero 2005). In this sense, one's friendship circles in fact largely indicate one's social position. The change of one's social circles, hence, more or less indicates one's social mobility, and vice versa.

Nonetheless, in spite of the significant changes to their friendship circles, the economic success of the interviewees did not bring better social integration. Their social interactions beyond kin were mainly circumscribed to rural migrants. Few had established contacts with the locals in Beijing. The distant relationships between these two groups might be partly due to their different occupations and lifestyles. The interviewees usually left home very early in the morning and returned very late, without taking any breaks on weekends or holidays, except for the Spring Festival. This hectic work life inevitably constrained their opportunities to get to know their neighbors. Perhaps more important, however, was the low opinion that the locals held toward rural migrants. The urbanite attitude of superiority not only impeded relationships between the two parties but also reinforced feelings of exclusion on the migrant side. It goes without saying, however, that rejection on the part of locals meant that these businesspeople were socially isolated. Instead, given the large number of rural migrants in Beijing, the interviewees still enjoyed many opportunities to socialize with people in similar positions. Their social adaptation therefore was largely a process of assimilating with social groups formed by people similar to themselves rather than a process of integrating into the already established urban classes.

These findings indicate that economic positions and social positions do not exist in a tight fit. The economic success of the interviewees did not lead to an equivalent change in their social positions. The loose relationship between economic and social positions reminds us of the limitations of conventional class analysis approaches that focus primarily on economic criteria in defining class divisions (Goldthorpe et al. 1987; Wright 1997). Social status, which is often neglected in class schemas, was found to play an important role, and it deserves more serious consideration. These findings also have significant implications for the study of stratification and class formation in contemporary China. With the re-emergence of some previously eliminated social classes, a new middle class is forming. Considering the dual social system China has implemented, however, the newly emerging middle-class is likely to be segmented, with wide divisions between migrants and nonmigrants. This will be a particularly interesting topic for class formation studies in China. 


\section{Acknowledgements}

The author would like to thank all the participants in this research for their willingness to share their stories with her. She is also grateful to Liu Yuming, Liu Shuqin, and Emily Wang for their kind help, as well as the anonymous reviewers and the editor, for their constructive feedback and helpful comments.

\section{Authors' contributions}

The sole author, NL, contributed to the paper independently. The author read and approved the final manuscript.

\section{Funding}

This research is supported by the China University of Political Science and Law (Funding No.: 152FG84001).

\section{Availability of data and materials}

This research is based on the author's fieldwork. The data generated through fieldwork are included in this manuscript.

\section{Competing interests}

The author declares that she has no competing interests.

Received: 26 December 2018 Accepted: 4 September 2019

Published online: 23 October 2019

\section{References}

Anwar, M. 2002."Social Networks of Pakistanis in the UK - A Re-evaluation,"Social Networks - Critical Concepts in Sociology 3. Ed. Scott, J. London: Routledge

Barnes, J.A. 2002. In "Class and committees in a Norwegian Island parish," social networks_critical concepts in sociology 2, ed. J. Scott. London: Routledge.

Blau, P.M. 1956. Social mobility and interpersonal relations. American Sociological Review 21 (3): 290-295.

Blau, P.M. 1964. Exchange and power in social life. New York: Wiley.

Bott, E. 2002. In "Urban family_conjugal roles and social networks" social networks_critical concepts in sociology 2., ed. J. Scott. London: Routledge.

Bottero, W. 2005. Stratification-social division and inequality. London and New York: Routledge.

Bourdieu, P. 1984. Distinction — a social critique of the judgment of taste. London, Melbourne and Henley: Routledge \& Kegan Paul.

Devine, F. 1992. Affluent worker revisited_privation and the working class. Edinburgh: Edinburgh University Press.

Fei, H.T. 1985. Xiangtu Zhongguo (Earthbond China). Beijing: Sanlian Publisher.

Finch, J. 1989. Family obligations and social change. Oxford: Polity Press.

Fukuyama, F. 1995. Trust - The social virtues and the creation of prosperity. London: Hamish Hamilton.

Goldthorpe, J.H., C. Llewellyn, and C. Payne. 1987. Social mobility and class structure in modern Britain. Oxford: Clarendon Press.

Higginbotham, E., and L. Weber. 1992. Moving up with kin and community: upward social mobility for Black and White women. Gender and Society 6 (3): 416-440.

Li, C.L. 2011. The development of China's middle classes. Heilongjiang Social Sciences 1: 75-87.

Li, P.L. 2003. Social network of rural migrants in China. Social Science in China 4: 138-148.

Li, P.L. 2017. An analysis on childcare in urban China. Population and Family Planning. 06: 18-19.

Lipset, S.M., and R. Bendix. 1967. Social mobility in industrial society. Berkeley and Los Angeles: University of California Press.

Lu, X.Y. 2004. Social mobility in contemporary China. Beijing: Social Sciences Documentation Publishing House.

Ma, C.H., J.Q. Shi, Y.h. Li, et al. 2011. Family change in urban areas of China: main trends and latest findings. Sociological Studies. 2: 182-216

Ma, D.D. 2015. The emerging middle classes community in China. Tribune of Social Sciences. 6: 168-184.

Ma, L.J., and B. Xiang. 1998. Native place, migration and the emergence of peasant enclaves in Beijing. China Quarterly 155: 546-581.

National Health Commission of the People's Republic of China. 2018. The 2018 report on China's migrant population development.

Ritzer, G., and D. Goodman. 2003. In Sociological theory, ed. I.L. Burr Ridge et al. Boston: Mc Graw Hill.

Solinger, D.J. 1999. Contesting citizenship in urban China-peasant migrants, the state, and the logic of the market. Berkeley: University of California Press.

Song, G.W. 2017. A discussion on the housing issue. Gansu Agriculture. 8: 44-45.

Sorokin, P. 1998. Social mobility. London: Routledge Thoemmes Press.

Tang, C., and W.Q. Chen. 2012. The kinship relations of urban families in China: a study on family structure and family relationships in five cities. Jiangsu Social Sciences. 2: 92-103.

Wang, Z., F.Z. Zhang, and F.L. Wu. 2016. Intergroup neighboring in urban China: implications for the social integration of migrants. Urban Studies 53 (4): 651-668.

Wellman, B. 2002a. In "Structural analysis—from method and metaphor to theory and substance," Social Networks-critical concepts in sociology 1, ed. J. Scott. London: Routledge.

Wellman, B. 2002b. In "The community question: the intimate networks of east Yorkers," social networks_critical concepts in sociology 2, ed. J. Scott. London: Routledge.

Wellman, B. 2002c. In "The place of kinfolk in personal community networks," social networks_critical concepts in sociology 3 , ed. J. Scott. London: Routledge.

Wright, E.O. 1997. Class counts: Comparative studies in class analysis. Cambridge: Cambridge University Press.

Xiang, B. 2005. Transcending boundaries—Zhejiangcun: The story of a Migrant Village in Beijing. Leiden: Koninklijke Brill NV.

Xiao, Y. 2014. Chaxu Geju and the modern transformation of the Chinese society. Exploration and Free Views. 6: 48-54.

$\mathrm{Xu}, \mathrm{Q}$. 2015. Sons or daughters? Who are caring for aging parents? A gender comparative study of Chinese family. Society. 4: 199-219.

Yan, Y.X. 2003. Private life under socialism: love, intimacy, and family change in a Chinese Village, 1949-1999. Stanford: Stanford University Press. 
Yang, S.H., and H.R. Hou. 1999. Blood relations, marriage relations, affection and interest: the rationalization trend of Chaxu Geju in contemporary rural China. Social Sciences in Ningxia. 6: 51-58.

Yue, Z.S., S.Z. Li, X.Y. Jin, and W.M. Feldman. 2013. The role of social networks in the integration of Chinese rural-urban migrants: a migrant-resident tie perspective. Urban Studies 53 (9): 1704-1723.

Zhang, L. 2001. Strangers in the City-reconfiguration of space, power, and social networks within China's floating population. Stanford: Stanford University Press.

Zhang, W.H. 2008. Differential order in the social network of urban residents. Journal of Jiangsu Administration Institute. 1: 67-72.

Zhou, F.Z. 2018. Values of social action in the Guanxi society: a path towards localization for Chinese sociology. Sociolinguistic Studies 1: 41-62.

\section{Publisher's Note}

Springer Nature remains neutral with regard to jurisdictional claims in published maps and institutional affiliations.

Submit your manuscript to a SpringerOpen ${ }^{\odot}$ journal and benefit from:

- Convenient online submission

- Rigorous peer review

- Open access: articles freely available online

High visibility within the field

- Retaining the copyright to your article 